\title{
Pollination Ecology and BREeding System OF DELPHINIUM OCCIDENTALE
}

\author{
RON SCOGIN $\bullet$ RANCHO SANTA ANA BOTANIC GARDEN \\ ClaREMONT GRADUATE SCHOOL $\bullet$ ClaREMONT
}

\section{INTRODUCTION}

Delphinium occidentale Nutt. (Ranunculaceae), the tall larkspur, occurs sporatically as isolated local populations in moist locations at lower and middle elevations of Grand Teton National Park. Individual plants of this species exhibit flowers which occur as one of three distinct color morphs and which occur mixed in the local populations. The three floral morphs are 1) plants exhibiting the most familiar, uniformly dark purple pigmented flower form, 2) plants exhibiting an all white, nonpigmented, albino form, and 3) plants whose flowers are intermediate in form between the extremes of 1) and 2), a semi-albino form which exhibits normally pigmented petals, but white, nonpigmented sepals.

The occurrence of mixed, polymorphic populations of $D$. occidentale floral morphs can be rationalized by two alternative hypotheses:

1. A stable, balanced polymorphism exists among the three morphs. This polymorphism is actively maintained by selective pressures, probably on some aspect of the reproductive biology (perhaps pollination ecology) of the floral morphs, or

2. The distribution of polymorphs is merely a founder effect, reflecting the distribution of morphs present in the seed collection which initially established the colonizing population.

The research undertaken during 1993 represents an effort to discriminate between these alternative explanations of flower color polymorphism in D. occidentale.

\section{$\checkmark$ RESEARCH STRATEgY}

The strategic approach to investigating this problem involved two studies:

1. A census of the floral morphs of several large populations of $D$. occidentale in order to determine whether any evidence exists that diverse populations are converging on a uniform frequency distribution of floral morphs, as might be expected if polymorphism were actively driven by features of reproductive ecology, and

2. An effort to measure comparative aspects of the reproductive ecology of the three morphs in order to determine whether any significant fitness differences exist among them which might be selectively acted upon to alter morph frequencies over time.

Reproductive biology parameters which were examined among morphs included the following:

a. Resource allocation to reproduction for each morph

1. the number of inflorescences per plant

2. the number of flowers per inflorescence

b. Reproductive success of each morph 1. the number of ovules per ovary 2 . the number of seed per follicle 


\section{$\checkmark \quad$ MATERIALS}

Four large populations of $D$. occidentale were examined with respect to frequencies of floral morphs and features of reproductive ecology.

1. Two Ocean Lake: The largest population known to the investigator within Grand Teton National Park. This population is located 1 mile south of Two Ocean Lake along the road to Two Ocean Lake.

2. Antelope Flats: Along Antelope Flats Road just north of Blacktail Butte, 1/4 mile east of Jackson Hole Highway.

3. Sawmill Ponds: At the Sawmill Ponds, 3/4 mile west of the Moose Visitor Center along the Moose-Wilson Road.

4. Phelps Lake: Along the side of the Moose-Wilson Road, 2 miles west of the Moose Visitor Center.

\section{$\checkmark \quad$ RESUlts}

Censuses of the four investigated populations revealed frequencies of floral morphs depicted in Table 1.

\begin{tabular}{lllll}
\hline \multicolumn{1}{l}{ Table 1. Floral morph frequencies of $D$. occidentale among four populations. } \\
\hline Population & Pigmented & Semi-albino & Albino & $\begin{array}{l}\text { Total } \\
\text { Counted }\end{array}$ \\
\hline Two Ocean Lake & 0.717 & 0.280 & 0.002 & $\begin{array}{l}357 \text { (population } \\
\text { estimate ca. } \\
5000-6000)\end{array}$ \\
Antelope Flats & 0.977 & 0.023 & 0.000 & $\begin{array}{l}310 \quad \text { (total } \\
\text { population) }\end{array}$ \\
Sawmill Ponds & 0.506 & 0.494 & 0.00 & $\begin{array}{l}538 \text { (population } \\
\text { estimate ca. } \\
2000)\end{array}$ \\
Phelps Lake & 0.015 & 0.972 & 0.012 & $\begin{array}{l}653 \text { (total } \\
\text { population) }\end{array}$
\end{tabular}

Table 2 summarizes the measured reproductive ecology parameters of $D$. occidentale among several populations.

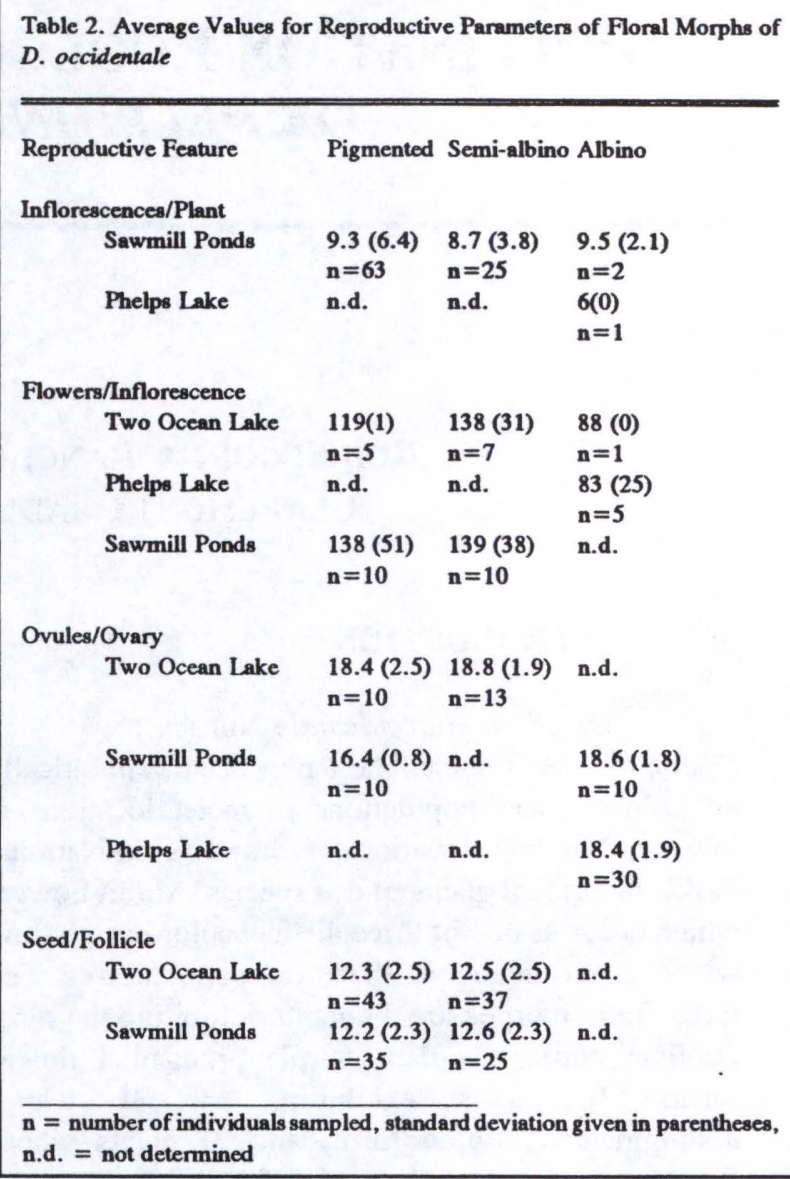

Table 2. Average Values for Reproductive Parameters of Floral Morphs of D. occidentale

\begin{tabular}{|c|c|c|c|}
\hline Reproductive Feature & Pigmented & Semi-albino & Albino \\
\hline \multicolumn{4}{|l|}{ Inflorescences/Plant } \\
\hline Sawmill Ponds & $\begin{array}{l}9.3(6.4) \\
\mathrm{n}=63\end{array}$ & $\begin{array}{l}8.7(3.8) \\
\mathrm{n}=25\end{array}$ & $\begin{array}{l}9.5(2.1) \\
n=2\end{array}$ \\
\hline Phelps Lake & n.d. & n.d. & $\begin{array}{l}6(0) \\
n=1\end{array}$ \\
\hline \multicolumn{4}{|l|}{ Flowers/Inflorescence } \\
\hline Two Ocean Lake & $\begin{array}{l}119(1) \\
n=5\end{array}$ & $\begin{array}{l}138(31) \\
n=7\end{array}$ & $\begin{array}{l}88(0) \\
n=1\end{array}$ \\
\hline Phelps Lake & n.d. & n.d. & $\begin{array}{l}83(25) \\
n=5\end{array}$ \\
\hline Sawmill Ponds & $\begin{array}{l}138(51) \\
n=10\end{array}$ & $\begin{array}{l}139(38) \\
n=10\end{array}$ & n.d. \\
\hline \multicolumn{4}{|l|}{ Ovules/Ovary } \\
\hline Two Ocean Lake & $\begin{array}{l}18.4(2.5) \\
n=10\end{array}$ & $\begin{array}{l}18.8(1.9) \\
n=13\end{array}$ & n.d. \\
\hline Sawmill Ponds & $\begin{array}{l}16.4(0.8) \\
n=10\end{array}$ & n.d. & $\begin{array}{l}18.6(1.8) \\
n=10\end{array}$ \\
\hline Phelps Lake & n.d. & n.d. & $\begin{array}{l}18.4(1.9) \\
n=30\end{array}$ \\
\hline \multicolumn{4}{|l|}{ Seed/Follicle } \\
\hline Two Ocean Lake & $\begin{array}{l}12.3(2.5) \\
\mathrm{n}=43\end{array}$ & $\begin{array}{l}12.5(2.5) \\
\mathrm{n}=37\end{array}$ & n.d. \\
\hline Sawmill Ponds & $\begin{array}{l}12.2(2.3) \\
\mathrm{n}=35\end{array}$ & $\begin{array}{l}12.6(2.3) \\
n=25\end{array}$ & n.d. \\
\hline
\end{tabular}

\section{DISCUSSION}

The interpretation of the results obtained during 1993 are presented below as a narrative response to a series of explicit questions.

1. Is the frequency of floral color morphs changing within populations over time?

A preliminary survey of floral morph frequencies in the Two Ocean Lake population was performed in 1986 and revealed frequencies of 0.697 , 0.301 , and 0.002 for pigmented, semi-albino, and albino forms, respectively. After a period of seven years (1993) the corresponding frequencies in the same population were determined as $0.717,0.280$, and 0.002 for the pigmented, semi-albino, and albino morphs, respectively. The striking agreement in frequencies between these two censuses suggests that no rapid change in floral morph frequency values is occurring within the Two Ocean Lake population. 
This result might be expected since $D$. occidentale is a perennial herb with a multi-year lifetime and the Two Ocean Lake population is a large and stable (perhaps enlarging) population. In such a population, floral frequency changes would be expected to change slowly. Such a result would also be predicted if the reproductive fitnesses of all floral morphs were very nearly the same. The Two Ocean Lake population is so large (estimated at several thousands of individuals) that a total count of individual plants was not attempted in 1986 or 1993, but an ancedotal impression is that the population has expanded in both number of individuals and in area inhabited during this time interval.

As shown in Table 1, the frequencies among morphs vary widely from population to population and only subsequent censusing can demonstrate that each population is stable with respect to morph frequency.

2. Is the total number of viable seeds set limited by pollinator availablility?

Results from preliminary studies performed in 1986 revealed the number of ovules/ovary in pigmented flowers of the Two Ocean Lake population to be 11.6 and the corresponding number of seed/follicle to be 12.4. These results suggested that seed set is not limited by pollinator availability (i.e., virtually every ovule develops into a seed).

Table 2 shows the values of ovules/ovary and seed/follicle found during 1993 field studies of all three floral morphs from three populations. The number of ovules/ovary is not different among morphs, but is higher (average value of 18.2) than the value noted in 1986 (11.6). By contrast, the number of seed/follicle is identical (12.4) to the value noted in 1986 and is not different between morphs or populations. Since realized seed set was less than potential seed set in 1993, one possible interpretation is that seed set is limited by pollinator availability. Such an interpretation must be made with caution, however, because climatic conditions during 1993 were unusual. A long, wet winter resulted in a peak of flowering timing which was delayed by at least two weeks from a typical season. Pollinators (hummingbirds and bees) were noticably less numerous than in previous years, perhaps due to anomalous seasonality. Seed set numbers, thus, must be viewed with caution, but suggest that seed set may be pollinator limited. Further studies including hand pollination/bagging experiments could confirm this conclusion.

3. Are there differences in total reproductive output (i.e., total number of flowers/plant) among the three floral morphs?

Two factors influence the total reproductive output of a particular floral morph: 1) the number of floral inflorescences per plant and 2) the number of flowers per inflorescence. Values for these two parameters are presented in Table 2 for all three floral morphs in three populations. The number of inflorescences/plant is similar among the three floral morphs in the Sawmill Ponds population and suggests that no difference exists among morphs with respect to this reproductive parameter. A cautionary note regarding this parameter should be emphasized. Delphinium occidentale is a perennial herb and the number of inflorescences per plant appears to be strongly age dependent. Many scattered, isolated $D$. occidentale plants were observed at various locations in the park which exhibited only one or a few inflorescences. These were taken to represent young, recent colonizers who will increase in reproductive output as they mature. Thus, whereas comparisons of inflorescences/plant are valid within a stable population, values for this parameter between populations may not be comparable due to different ages and age structures among the populations.

The second factor affecting total reproductive output is the number of individual flowers per inflorescence. As shown in Table 2, the values of this parameter for pigmented and semi-albino flowers is the same (138.6 and 133.8, respectively), whereas that for albino flowers is significantly lower (84.4).

When these two parameters are multiplied together, the result is the total reproductive output for the floral morph (namely, the number in individual flowers per plant). Those values are 1244, 1205, and 801 for pigmented, semi-albino, and albino plants, respectively. Thus, the total resource allocation by pigmented and semi-albino plants is comparable, whereas that for albino plants in significantly less.

4. Are the relative frequencies of floral morphs uniform among populations? 
The result of censuses of floral morph frequencies among four populations of $D$. occidentale is shown in Table 1. These censuses reveal dramatic differences in floral morph frequency values among populations. The results presented in question \#1 above, suggest that morph frequencies in a population are stable over intermediate time intervals (decades). Delphinium occidentale is a long-lived perennial which could yield very slowly shifting morph frequencies within a population, but there is no present evidence that intrapopulational morph frequencies change over time.

\section{- CONCLUSIONS}

Based on results of 1993 field observations, it can be provisionially concluded that the floral morph frequency of a population of $D$. occidentale is stable over intermediate time intervals and not strongly influenced by factors of reproductive ecology. The observed varying frequencies of floral types reflect the relative frequencies of seed of the various morphs in the population founding event--i.e., morph frequencies are a founder effect. The primary seed disperser of these plants has been reported to be migrating elk (Murie and Murie, 1985). Since no factor in the pollination ecology of $D$. occidentale is strongly morph dependent (with the possible exception of flowers/inflorescence in albino plants), pollinator behavior and reproductive ecology does not appear to alter populational morph frequencies. It would appear that an operating hypothesis for observed floral polymorphism among $D$. occidentale populations is that it reflects the random browsing habits of seed dispersers (elk) who establish the founder population with varying, stable frequencies of floral morphs.

\section{- Literature Cited}

Murie, M. and O. Murie. (1985). Wapiti Wilderness (p.296-297). Colorado Associated University Press, Boulder, Colo. 302 pp. 